\title{
Discussion on the Design of Fixable Directional Grater
}

\author{
Zhao Zhanfeng \\ Wenzhou Vocational \& Technical College, Wenzhou. 325035 \\ Zhanfeng@qq.com
}

Keywords: Flexible, Grater, Function, Design.

Abstract: Grater, as one of the kitchen utensils can help to cut vegetables or fruits into an expected patterning during cooking in an easy way. It not only can provide human convenience in our life and also acts as the path for us to enjoy life. It is the actual presentation of advanced technology. From many aspects such as function, modeling, material, structural, technology and art, the grater is designed to help to cook easier. With profound theoretical basis and wide application value, it perfectly shows the close combination of ergonomics and design. The design of grader can drive the further theoretical study in the design field of kitchen utensils in our country and development and design of the industrial products for kitchen utensils.

\section{Introduction}

Currently, as a necessary tool in our kitchen, grater can provide a convenient way to carry out kitchen activities. By using it, we shorten the time to cook some foods with complex making steps like dumplings and simplifies the cook way. In our rush life full of huge working pressure, a simple and quick tool which can bring happy and fun in life plays an important role to reduce living pressure.

In the past, the initial grater with simple structure by using metal material to form a cuboid main body was easy to operate, making our life easier. Currently, grater in market has changed a lot in the structure and function. It can not only to provide service for dumplings and also be designed with cutting function to make materials for some simple dishes, bringing an easier cooking.

The grater is a kind of manual tool, which closely connects to our hands and mind. A frequent use of such tool draws more attention to participate in cooking, improving dietetic level and health life style.

\section{Innovation Points}

1) Focusing on the innovation, we create new use ways and functions based on previous design to realize easier operation and multiple use functions.

2) During the whole design, we always insist on and meet the principle of green design and consider protecting environment and saving resources.

3) Our design combining the product semantics aims to make the description of product clear and simple, so that people can understand it more direct. 
4) Using the traditional stitching design, we has explored a good design plan for better splitting and splicing of products, presenting the traditional advantageous design technology of China.

5) On the basis of ergonomics, the using part of human and product structure are under consideration, so we choose the hand as important part to study and establish a use way which meets the ergonomics. In addition, we consider the stress on using part and posture of the hand to reduce fatigue.

6) Based on previous design, we obtain a new way to improve the application performance of product and put forward a workable plan to extend product life cycle.

7) During the product design, with the design principle of convenient, we control the modeling of product, including its space occupation, and we use its modeling to decorate kitchen.

8) We explore a new holding way to protect skin tissue of hand, so that we can reduce the psychological burden to use and enjoy a comfortable use experience.

9) For the safety, we search for an effective way to protect hands and reduce materials to be used.

\section{Design Plan}

Firstly, we study the functions. By classifying the vegetable types, we choose the single vegetable, for which, the working mode of pencil sharpener is used. First, we fix the vegetable and then rotate the cutting tip to cut up vegetable. Below the cutting space, there is a space to storage and collect the chopped vegetable. The cutting tip can be removed to clear. During the working time, fix the vegetable on the rotating disk first, hold and turn the handle continuously. There is a slide rail under the fixed part which can keep feeding when the front part of vegetable has been cut, as shown in Figure 1.

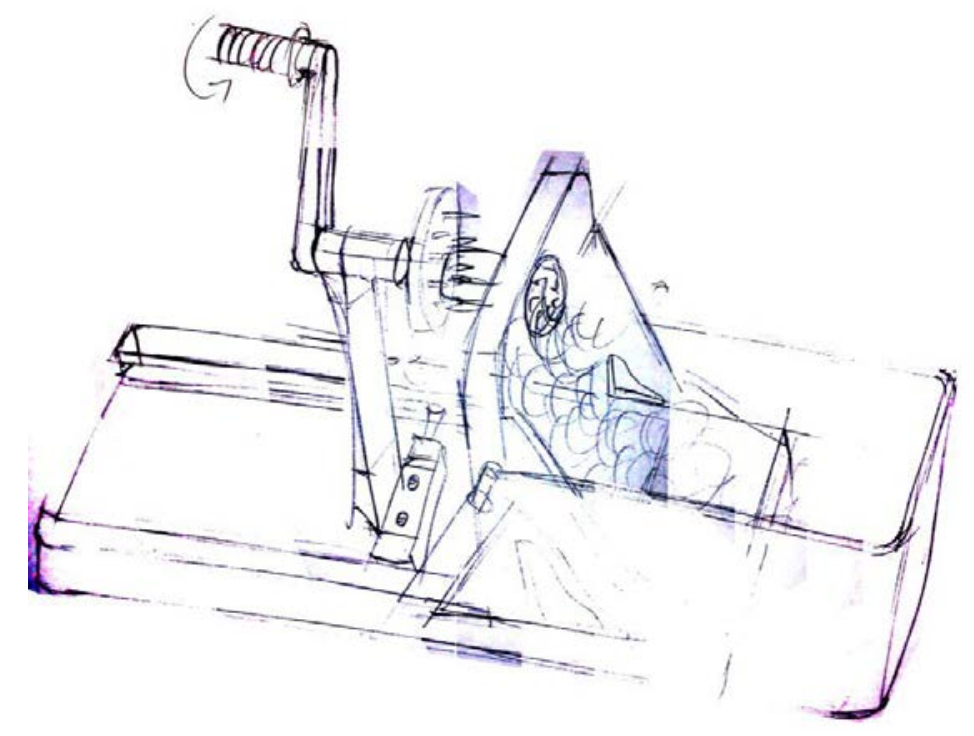

Figure 1 Rotary Type

The second plan is an extension and breakthrough to the function of grater. Compared with the first plan, we study the modeling and applicable scope of product, with attention paid to the function and modeling of grater.

The product acquired has a small application and usage, and it cannot cut smoothly the vegetables like cabbage etc. Instead, it may cause damage to operating tools. Besides, aesthetically, the plan I is away from the aesthetic requirements. In terms of the design, different design ways are used to improve the initial grater. 
On modeling, we choose the previous grater modeling but develop the function of it. The previous grater can only be used to cut hard single vegetables, however, our plan II considers the vegetables to be cut such as cabbage, leading to a bigger use scope.

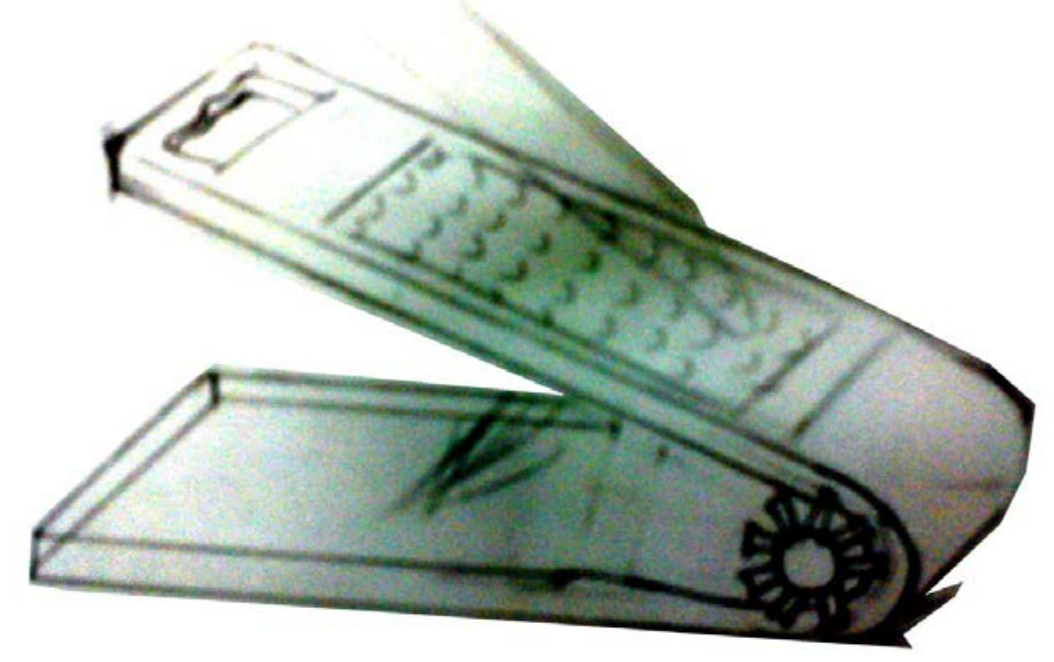

Figure 2 Slope Type

\section{Modeling of Grater}

Modeling, the image of an object, is a kind of visual language expressed with lines as main symbols in object form. The modeling element is an important part to be considered in design concerns. The nature and features of designs should be defined, specific and tangible through a certain modeling. For a long time, the industrial designed had been called as "industrial modeling". As not scientific and standard is it, it shows that how important the modeling is in design and what is the noticeable. Modeling embodiment means the idea of modeling will be given on product, to make it as an identification mark with its specific modeling. When people know the product and the model of it will be mastered, and the model will come into the mind naturally. Sometimes, the expression of function will also be realized through model. Once the consciousness of functional model forms, it will become an identification feature of this type of product. The model of grater is a good function expression. In our days, the tip of grater in market keeps its previous model so that product categories can be identified by customers quickly.

The function of grater is well-expressed on the tip model, enabling the tip become a feature to be identified. The whole features of it still keep its own way, no special modeling, so the design of grater mainly focus on its modeling and the way to fix vegetable. For the tip, we has not changed it.This grater is a totally breakthrough in design of its original modeling, from the function to modeling. With the rotary movement, the rotational tip will cut vegetables in fraction mode, so the force of friction between tip and vegetables is important. Compared with previous tip part of grater, the property has much less cutting points, which reduce the force of friction between them so that the vegetables can be cut smoothly without any holdback to rotary tip.

The whole modeling of grater looks like a cylinder, which provides adequate rotary movement space. By perfect combination of two cylinders, it can reduce the burden of thinking because the cylinder model will bring a feel of stable and safe. Since it is a little dangerous to shred vegetables or make them into other shapes, a stable model will make customer feel relieved. 


\section{Functions of Grater}

As necessary tools in our daily life, kitchen utensils have many different types according to using properties; in addition, with the difference in material and structure, these tools are exposed with various functions. Grater is a tool to help to cut vegetables or fruits into expected shapes in a quick way in cooking. It not only can provide human convenience in our life and also acts as the path for us to enjoy life. It is the actual presentation of advanced technology. From many aspects such as function, modeling, material, structural, technology and art, the grater is designed to help to cook easier. With profound theoretical basis and wide application value, it perfectly shows the close combination of ergonomics and design. The design of grader can drive the further theoretical study in the design field of kitchen utensils in our country and improve development and design of the industrial products of kitchen utensils. In our rush life full of huge working pressure, a simple and quick tool which can bring happy and fun in life plays an important role to reduce living pressure.

\section{Materials of Grater}

Materials are the physical basis for living and developing of human. It is used to make products, devices, structures, machines and other things. In the 1970s, information, material and energy were regarded as three pillars. Coming into 21st century, new materials, as the basis and leader of high-tech, are widely used in our life. Together with information, biotechnology, they become the most important fields to be developed in new century.

Because of the variety characteristics of material, there is no unified standard to define them. From the aspects of physical and chemical properties, they can be divided into metal, non-metal materials and the composite materials composed of organic polymer materials and different types of materials. Different materials are adopted according to the functions of each part of grater. The tip of grater is metal material, only pure gold or alloy, which presents microcrystalline structure. It has metal luster and good mechanical property; besides, this metal can be processed. With high hardness and good wear resistance, it can be used to make thin shell. Therefore, a metal tip is an ideal choice. The side to fix vegetables is polypropylene plastics. Such material is milky white and translucent, non-toxic and tasteless. With light weight and good fatigue performance, it is a good material for kitchen ware. Organic glass is used for shell of grater. This kind of glass is light and non-breakable. With high transparency, it is easy to be colored. It has good strength, water resistance, weather resistance, electrical insulation and thermos-plasticity. Therefore, it is widely used for making household implements.

\section{Structure of Grater}

The structure design of the grater is greatly different from that of initial grater. Externally, it has two spliced cylinders. On the outer side of top of the upper cylinder, there is a rotary pressing part, under which, a rotary bar is provided. During operation, you can press down the part; then the tip of grater will rotate to cut. Inside of the top, there is part to fix vegetables. As the press bar moves down, the vegetable will be driven to move. The tip connects to lower part of grater. The connecting part has a smooth ball, a key part for supporting tip rotation. At lower part of the grater, there is a big space to collect separated vegetables to reduce unnecessary waste.

For the internal structure, it is complicated in the design of working mode. The space occupied is limited, and inside a spring is provided to offer great cutting strength so that only a little force can finish cutting easily. While the outer structure is simple and it is easy to take. In a word, the design of the grater is a perfect combination of simple and complicated. 


\section{Conclusion}

The grater represents the wisdom of human. Its structure shows the flexible rational thinking, which is expressed in a specific product, realizing the transfer from theory to practice. The innovated structure of grater marks the improvement in scientific technology and continuous new materials and technology drive the development of grater.

Up to today, the grater has various types, which is mainly classified to manual and auto modes aimed to cut smoothly and meet the human's requirements on food. The design of grater is industrial design and its final purpose is to benefit our life, to help us have a safer, more healthy and technical working mode. Our life changes with the development and progress of time and society, thus designs has always focused on the changes in life style. With the changes as creating source for design, they create graters which are suitable for current working mode. Furthermore, they attempt to create more advanced and civilized working mode.

In the information age, things changes from time to time and also, this is a gold age for designers to bring their best out. From some points, history of industrial design matches up the development of modern materials and technology, and for the design style, its change is closely affected by the change of material with different properties. In our days, designers, as the core to develop new materials and technologies, should make the properties of new findings fully expressed on the grater design, to realize the design innovation of this product, to make it to express time spirit.

\section{References}

[1]Samira Bourgeois-Bougrine,Stéphanie Buisine,Claire Vandendriessche,Vlad Glaveanu,Todd Lubart. Engineering students' use of creativity and development tools in conceptual product design: What, when and how? [J]. Thinking Skills and Creativity,2017,24.

[2]Manuel Ramsaier,Claudius Spindler,Ralf Stetter,Stephan Rudolph,Markus Till. Digital Representation in Multicopter Design Along the Product Life-cycle[J]. Procedia CIRP,2017,62.

[3]Sorina Morar-Mitrica,Monica L. Adams,George Crotts,Christine Wurth,Peter M. Ihnat,Tanvir Tabish,Valentyn Antochshuk,Willow DiLuzio,Daniel Dix,Jason Fernandez,Kapil Gupta,Michael S. Fleming,Bing He,James K. Kranz,Dingjiang Liu,Chakravarthy Narasimhan,Eric Routhier,Kathy Taylor,Nobel Truong,Elaine Stokes. An Intercompany Perspective on Biopharmaceutical Drug Product Robustness Studies[J]. Journal of Pharmaceutical Sciences,2017.

[4]Francesca Buttini,Stavroula Rozou,Alessandra Rossi,Vera Zoumpliou,Dimitrios M. Rekkas. The application of Quality by Design framework in the pharmaceutical development of dry powder inhalers[J]. European Journal of Pharmaceutical Sciences,2017.

[5]Huimeng Zheng,Weidong Liu,Chengdi Xiao. An activity-based defect management framework for product development [J]. Computers \& Industrial Engineering,2018,118.

[6]Agnese Piselli,Weston Baxter,Michele Simonato,Barbara Del Curto,Marco Aurisicchio. Development and evaluation of a methodology to integrate technical and sensorial properties in materials selection[J]. Materials \& Design,2018,153.

[7]Andrey Kutin,Vitaly Dolgov,Mikhail Sedykh,Sergey Ivashin. Integration of Different Computer-aided Systems in Product Designing and Process Planning on Digital Manufacturing[J]. Procedia CIRP,2018,67.

[8]Brown Mathew B,Digby-Bowl Caroline J,Todd Samuel D. Assessing Infant Carriage Systems: Ground Reaction Force Implications for Gait of the Caregiver.[J]. Human factors,2018,60(2).

[9]Boyce Heather,Smith Dan,Byrn Steve,Saluja Bhawana,Qu Wen,Gurvich Vadim J,Hoag Stephen W. In Vitro Assessment of Nasal Insufflation of Comminuted Drug Products Designed as Abuse Deterrent Using the Vertical Diffusion Cell.[J]. AAPS PharmSciTech,2018.

[10]Jian-Rong Tan. Special Issue on Innovative Design of Complex Products[J]. Chinese Journal of Mechanical Engineering,2018,31(1).

[11]David Peck,Prabhu Kandachar,Erik Tempelman. Critical materials from a product design perspective[J]. Materials and Design,2015,65.

[12]Ana Cristina Dias,Rita Almendra,Fernando Moreira da Silva. The Application of Ergonomic Knowledge by Undergraduate Product Design Students: FAULisbon as a Case Study[J]. Procedia Manufacturing,2015,3. 
[13]Zhenyu Zhang,Qingjin Peng,Peihua Gu. Improvement of User Involvement in Product Design[J]. Procedia CIRP,2015,36.

[14]R.J. Odora. Integrating Product Design and Entrepreneurship Education: A Stimulant for Enterprising Design and Engineering Students in South Africa[J]. Procedia Technology,2015,20.

[15]Chung-Yang Chen,Gen-Yih Liao,Ku-Shen Lin. An attribute-based and object-oriented approach with system implementation for change impact analysis in variant product design[J]. Computer-Aided Design,2015,62.

[16]Shih-Wen Hsiao,Cheng-Ju Tsai. Transforming the natural colors of an image into product design: A computer-aided color planning system based on fuzzy pattern recognition[J]. Color Research \& Application,2015,40(6). 